http://jurnaltarbiyah.uinsu.ac.id/index.php/raudhah

e-mail: jurnalraudhah@uinsu.ac.id

p-ISSN: 2338-2163

e-ISSN: $2716-2435$

\title{
Strategi Guru Dalam Menangani Anak Yang Hiperaktif Melalui Terapi Permainan Puzzle Pada Kelompok A di Tk Swasta It Jabal Noor Medan Krio
}

\author{
${ }^{1}$ Abdul Aziz Rusman \\ UIN Sumatera Utara \\ ${ }^{2}$ Nunzairina \\ UIN Sumatera Utara \\ ${ }^{3}$ Dian Pertiwi \\ UIN Sumatera Utara
}

Article received : 22 Agustus 2021

Article accepted : 12 Oktober 2021
Review process : 21 September 2021

Article published : 01 Desember 2021

\begin{abstract}
Abstrak
Penelitian ini bertujuan untuk mengetahui strategi guru dalam menangani anak yang hiperaktif melalui terapi permainan puzzle pada kelompok A di TK Swasta IT Jabal Noor Medan Krio. Penelitian yang digunakan adalah penelitian jenis kualitatif. Subjek yang digunakan yaitu hanya anak hiperaktif pada kelompok A usia 4-5 tahun TK Swasta IT Jabal Noor yang berjumlah 3 orang anak. Penelitian ini menggunakan strategi guru dalam menangani anak yang hiperaktif melalui terapi permainan puzzle. Hasil penelitian siklus I diperoleh data perubahan anak yang hiperaktif perkembangan anak masih rendah. Dari 3 orang anak, 2 orang anak dikategorikan mulai berkembang dan 1 orang anak berkembang sesuai harapan . Pada siklus II dilaksanakan dengan memperbaiki kesulitan anak dalam mengukiti strategi guru dalam permainan puzzle untuk memperoleh peningkatan yang maksimal. Pada siklus ke II terjadi peningkatan yang signitifkan, dari 1 anak kriteria berkembang sangat baik sebanyak 2 orang, sedangkan kriteria berkembang sesuai harapan sebanyak 1 orang anak. Anak yang memperoleh kriteria mulai berkembang tidak ada dan anak yang memperoleh kriteria belum berkembang tidak ada.
\end{abstract}

Kata Kunci : Anak Hiperaktif, Terapi, Permainan Puzzle

\begin{abstract}
The purpose of this study was to determine the teacher's strategy in dealing with hyperactive children through puzzle game therapy in group A at the IT Jabal Noor Private Kindergarten Medan Krio. The research used is a qualitative type of research. The subjects used were only hyperactive children in group A aged 4-5 years in Jabal Noor IT Private Kindergarten, totaling 3 children. This study uses the teacher's strategy in dealing with hyperactive children through puzzle game therapy. The results of the research cycle I obtained data on changes in children who are hyperactive, child development is still low. Of the 3 children, 2 children were categorized as starting to develop and 1 child developing as expected. In cycle II, it was carried out by correcting the difficulties of children
\end{abstract}

Strategi Guru Dalam Menangani Anak Yang Hiperaktif Melalui Terapi Permainan Puzzle Pada Kelompok A di Tk Swasta It Jabal Noor Medan Krio 
http://jurnaltarbiyah.uinsu.ac.id/index.php/raudhah

e-mail: jurnalraudhah@uinsu.ac.id

p-ISSN: 2338-2163

e-ISSN: $2716-2435$

in following the teacher's strategy in puzzle games to obtain maximum improvement. In the second cycle there was a significant increase, from 1 child the criteria developed very well as many as 2 people, while the criteria developed according to expectations as many as 1 child. There are no children who get the criteria for starting to develop and there are no children who get the criteria for not developing.

Keywords: Hyperactive Child, Therapy, Puzzle Games

\section{A. PENDAHULUAN}

Anak merupakan tumpuan sekaligus harapan dari semua orang tua. Anak merupakan satusatunya penerus bangsa yang mempunyai tanggung jawab besar demi tercapainya cita-cita bangsa. Setiap anak memiliki karakteristik tertentu yang khas dan tidak sama dengan orang dewasa, mereka selalu aktif dan ingin tahu terhadap apa yang dilihat, didengar, dirasakan, mereka seolah-olah tidak pernah berhenti bereksplorasi dan belajar. Anak Usia Dini Adalah anak yang berusia 0-6 tahun yang melewati masa bayi, masa batitah, dan masa pra sekolah, perkembagan tersebut dapat berlangsung secara normal ataupun tidak normal. Pada masa usia dini ini sangat menentukan karakter dan kepribadian anak. Maka dari itu seorang guru dan orang tua harus bekerjasama dalam membentuk karakter anak yang baik, jika seorang guru dan orang tua tidak bekerjasama maka karakter anak tidak dapat terbentuk dengan baik dan perkembangan pada anak menjadi terhambat, maka perlunya perhatian guru dan orang tua terhadap perkembangan anak, khususnya pada perilaku hiperaktifnya, agar anak tersebut dapat mengontrol emosinya. Anak yang memiliki gangguan hiperaktif kemungkinan besar terjadi penghambatan pada perkembagannya, karena anak yang hiperaktif sering melakukan kegiatan yang tidak bermanfaat bagi anak, yang membuat konsentrasi belajar anak menjadi tidak baik dalam pembelajaran berlangsung.

Anak hiperaktif adalah anak yang sulit dalam berkonsentrasi, perhatianya sangat mudah beralih dari satu tempat ketempat yang lain, motorik berlebihan seperti anak suka berlari, berteriakteriak, dan susah mengikuti perintah. Anak yang hiperaktif mempunyai kesukaran untuk mengontrol perilakunya dan aktivitas yang dilakukan banyak tidak tepat, tidak pantas, dan anak melakukan itu sepanjang hari (Rafael Lisinus dan Pastiria Sembiring. 2020). Dampak bagi anak ketika di sekolah apabila perilaku hiperaktif ini tidak di tangani, maka anak akan menimbulkan hambatan penyesuaian perilaku sosial dengan kemampuan akademik siswa tersebut, karena dampak sosial dari perilaku hiperaktif dalam kehidupan anak adalah masalah sosial yang dialami anak yaitu kesulitan bergaul, sering terjadi konflik, terkadang tidak disukai oleh teman atau siswa lain, sering dihukum dan dimarahi oleh guru.

Strategi Guru Dalam Menangani Anak Yang Hiperaktif Melalui Terapi Permainan Puzzle Pada Kelompok A di Tk Swasta It Jabal Noor Medan Krio 
http://jurnaltarbiyah.uinsu.ac.id/index.php/raudhah

e-mail: jurnalraudhah@uinsu.ac.id

p-ISSN: 2338-2163

e-ISSN: $2716-2435$

Dalam dunia pendidikan anak usia dini, kegiatan bermain sambil belajar merupakan cara mereka untuk mendapatkan pengetahuan,keterampialan, dan juga nilai-nilai. Oleh karena itu, untuk menghadirkan pembelajaran yang menyenangkan dan bermakna untuk anak, maka guru dituntut agar memiliki kemampuan dan keterampilan dalam mengelola pembelajaran yang baik dan menyenangkan untuk anak (Khadijah dan Armanila. 2017).

Media puzzle adalah media permainan anak yang menarik dan menyenangkan yang akan meningkatkan kemampuan kognitif anak. Metode yang digunakan oleh guru di TK Swasta IT Jabal Noor Medan Krio untuk mengatasi anak yang hiperaktif adalah dengan cara terapi permainan puzzle. Berdasarkan hasil observasi di TK Swasta IT Jabal Noor Medan Kioad ada 1 kelas yang terdiri dari rentang usia 4-5 tahun. Keadaan siswa/siswi sekolah tersebut menunjukkan bahwa ada beberapa permasalahan yang berkaitan dengan tingkah laku yang berlebihan (Hiperaktif), beberapa diantaranya yaitu ada 3 orang anak yang tingkah laku nya berlebihan seperti anak yang sulit untuk tenang, anak hiperaktif sering berlari-lari, sering mengganggu teman-temannya saat di kelas dan diluar kelas, sering berteriak-teriak didalam kelas, anak susah mengikuti perintah, dan anak suka berpindah-pindah tempat.

Permainan puzzle sangat cocok digunakan oleh guru untuk mengatasi anak yang hiperaktif karean dengan kegiatan permainan puzzle dapat mengtrol sosial emosional anak, dapat menenangkan tingkah laku anak yang terlalu berlebihan seperti tidak berlari-lari, tidak mengganggu temannya. Hasil penelitian yang dilakukan Di TK Pratama Kids Sukabumi Bandar Lampung berdasarkan data awal anak hiperaktif kelompok A Di TK Pratama Kids Sukabumi Bandar Lampung dihari pertama peneliti mengamati anak di kelas saat proses belajar mengajar berlangsung, lalu dihari kedua peneliti mengamati anak yang mengalami hiperaktif dengan guru dengan hasil mulai membaik dan hasil penelitian terakhir dengan berdasarkan langkah-langkah yang sesuai dengan penanganan anak yang hiperaktif mendapatkan hasil yang maksimal ( Rosma,2019)

Hasil penelitian yang lain menyatakan bahwa anak Di Kelompok KB PAUD Saymara Kartasura menunjukkan bahwa dengan bermain puzzle anak termotivasi dan merasa senang, anak dapat lebih berkonsentrasi, mudah diatur dan dapat duduk dengan tenang mengikuti kegiatan. Karena permainan sangat disukai oleh anak. Dengan permainan, anak akan mengenal suatu konsep yang masih abstrak dapat lebih dikongkritkan, sehingga penerimaan tersebut menjadi gambaran bersifat ferbal. Salah satu permainan yang diberikan untuk anak hiperaktif adalah permainan puzzle karena merupakan salah satu permainan edukatif yang membutuhkan kesabaran dan ketekunan anak dalam merangkainya. ( Dwi Lestari, 2014)

Strategi Guru Dalam Menangani Anak Yang Hiperaktif Melalui Terapi Permainan Puzzle Pada Kelompok A di Tk Swasta It Jabal Noor Medan Krio 
http://jurnaltarbiyah.uinsu.ac.id/index.php/raudhah

e-mail: jurnalraudhah@uinsu.ac.id

p-ISSN: 2338-2163

e-ISSN: $2716-2435$

\section{B. METODE PENELITIAN}

Penelitian ini lakukan di TK Swasta IT Jabal Noor Medan Krio. Adapun waktu pelaksanaa penelitian ini yaitu pada semester genap dari bulan April Tahun Ajaran 2020/2021. Subjek penelitian ini yaitu anak usia 4-5 Tahim yang terdiri dari 1 kelas 19 orang anak. Sedangkan objek dalam penelitian ini yaitu strategi guru dalam menangani anak yang hiperaktif anak usia 4-5 tahun.

Metode yang digunakan dalam penelitian ini adalah penelitian kualitatif. Penelitian kualitatif ialah yaitu mendefinisikan suatu gejala, peristiwa, kejadian serta menjelaskan fenomena yang terjadi pada beberapa individu. Stauss dan Corbin menjelaskan Penelitian kualitatif merupakan jenis penelitian yang temuaanya tidak diperoleh melalui prosedur statistic atau bentuk hitungan lainnya. Meskipun datanya dapat dihitung dan disampaikan dalam angka-angka sebagaimana dalam sensus, analisis datanya bersifat kualitatif. Penelitian kualitatif merujuk pada analisis data nonmatematis, prosedur ini menghasilkan temuan yang diperoleh melalui data-data yang dikumpulkan dengan beragam sarana, antara lain wawancara, pengamtan, dokumentasi atau arsip, dan tes.

\section{HASIL TEMUAN DAN PEMBAHASAN}

Berdasarkan hasil observasi yang dilakukan oleh penulis bahwa dapat diketahui setiap melakukan kegiatan bermain selalu diadakan evaluasi kegiatan yang telah dilakukan. Agar kedepannya lebih baik dan bagus lagi, adapun kegiatan terapi permainan puzzle ini guru mengajak siswanya duduk berbentuk lingkaran untuk mengevaluasi terapi melalui permainan puzzle, apa saja kesulitan yang dilakukan oleh anak dengan cara mencontohkan dan mengulang kembali apa yang dimainkan anak, ketika guru mengulang menyusun kepingan-kepingan puzzle tersebut maka guru juga mengajak siswanya untuk membantu menyusun kepingan puzzle agar ada kerjasama antara guru dan murid atau antara murid dengan murid lainnya.

Berdasarkan observasi yang penulis lakukan mengenai data penanganan anak hiperaktif melalui terapi permainan puzzle di kelas A TK Swasta IT Jabal Noor Medan Krio maka penulis menyajikan data sebagai berikut :

Tabel 1. Data Awal Anak Hiperaktif Kelompok A di TK Swasta IT Jabal Noor Medan Krio

\begin{tabular}{|l|l|l|}
\hline No & \multicolumn{1}{|c|}{ Nama } & \multicolumn{1}{|c|}{ Masalah Anak } \\
\hline 1. & Aisyah & Anak sulit tenang ketika sedang membaca buku dan iqra'. \\
\cline { 4 - 5 } & & $\begin{array}{l}\text { Anak tidak mampu mempertahankan perhatian saat } \\
\text { mengerjakan tugas. }\end{array}$ \\
& & $\begin{array}{l}\text { Bermain tangan dan kaki atau bergerak di kursi ketika } \\
\text { mengerjakan tugas dari guru. }\end{array}$ \\
\cline { 3 - 4 } & $\begin{array}{l}\text { Anak tidak dapat mempertahankan perhatian dan penjelasan } \\
\text { dari guru. }\end{array}$ \\
\hline
\end{tabular}

Strategi Guru Dalam Menangani Anak Yang Hiperaktif Melalui Terapi Permainan Puzzle Pada Kelompok A di Tk Swasta It Jabal Noor Medan Krio 
http://jurnaltarbiyah.uinsu.ac.id/index.php/raudhah e-mail: jurnalraudhah@uinsu.ac.id

p-ISSN: 2338-2163

\begin{tabular}{|c|c|c|}
\hline & & $\begin{array}{l}\text { Anak suka bercerita dengan temannya pada saat mengerjakan } \\
\text { tugas. }\end{array}$ \\
\hline & & Anak suka berpindah-pindah tempat. \\
\hline \multirow[t]{9}{*}{2.} & \multirow[t]{9}{*}{ Daffa } & Anak sulit tenang ketika sedang membaca buku dan iqra'. \\
\hline & & $\begin{array}{l}\text { Anak tidak mampu mempertahankan perhatian saat } \\
\text { mengerjakan tugas. }\end{array}$ \\
\hline & & $\begin{array}{l}\text { Bermain tangan dan kaki atau bergerak di kursi ketika } \\
\text { mengerjakan tugas dari guru. }\end{array}$ \\
\hline & & $\begin{array}{l}\text { Anak tidak dapat mempertahankan perhatian dan penjelasan } \\
\text { dari guru }\end{array}$ \\
\hline & & $\begin{array}{l}\text { Anak suka bercerita dengan temannya pada saat mengerjakan } \\
\text { tugas. }\end{array}$ \\
\hline & & Anak suka berpindah-pindah tempat. \\
\hline & & Anak suka berlari- lari pada saat proses pembelajaran \\
\hline & & Anak suka berteriak-teriak saat bermain \\
\hline & & Anak susah mengikuti arahan guru \\
\hline \multirow[t]{9}{*}{3.} & \multirow[t]{9}{*}{ Naufal } & Anak sulit tenang ketika sedang membaca buku dan iqra’. \\
\hline & & $\begin{array}{l}\text { Anak tidak mampu mempertahankan perhatian saat } \\
\text { mengerjakan tugas. }\end{array}$ \\
\hline & & $\begin{array}{l}\text { Bermain tangan dan kaki atau bergerak di kursi ketika } \\
\text { mengerjakan tugas dari guru. }\end{array}$ \\
\hline & & $\begin{array}{l}\text { Anak tidak dapat mempertahankan perhatian dan penjelasan } \\
\text { dari guru }\end{array}$ \\
\hline & & $\begin{array}{l}\text { Anak suka bercerita dengan temannya pada saat mengerjakan } \\
\text { tugas. }\end{array}$ \\
\hline & & Anak suka berlari- lari pada saat proses pembelajaran \\
\hline & & Anak suka berteriak-teriak saat bermain \\
\hline & & Anak susah mengikuti arahan guru \\
\hline & & $\begin{array}{l}\text { Anak suka mengganggu temannya pada saat di kelas dan diluar } \\
\text { kelas }\end{array}$ \\
\hline
\end{tabular}

(Sumber : Hasil observasi pada saat survey di TK Swasta IT Jabal Noor Medan Krio)

Berdasarkan tabel 1.di atas data awal hasil observasi diatas pada sekolah TK Swasta IT Jabal Noor Medan Krio menunjukkan bahwa ketiga anak tersebut anak mengalami hiperatif. Pada penelitian ini penulis meneliti di kelas A yang berjumlah 19 peserta didik, tetapi peneliti fokus mengamati tiga peserta didik yang mengalami hiperaktif yaitu bernama Aisyah, Daffa, dan Naufal. Pengumpulan data dalam menganalisi penanganan anak hiperaktif di TK Swasta IT Jabal Noor Medan Krio menggunakan observasi, wawancara, dokumentasi, disini peneliti mengamati cara guru menangani anak yang hiperaktif melalui terapi permainan puzzle di kelas A.

Pada hari pertama peneliti mengamati anak di kelas A saat proses belajar mengajar berlangsung di TK Swasta IT Jabal Noor Medan Krio, beberapa anak tidak memperhatikan gurunya pada saat guru menjelaskan di depan kelas, berteriak-teriak didalam kelas pada saat belajar, bermain-main 
http://jurnaltarbiyah.uinsu.ac.id/index.php/raudhah

e-mail: jurnalraudhah@uinsu.ac.id

p-ISSN: 2338-2163

e-ISSN: 2716-2435

dengan kaki dan tangan atau bergerak-gerak dikursi, suka mengganggu temannya pada saat di kelas dan diluar kelas, dan susah mengikuti arahan guru.

Pada hari selanjutnya lebih kurang satu bulan sudah peneliti melakukan penelitian mengamati tiga anak yang mengalami hiperaktif dengan guru melakukan penanganan melalui terapi permainan puzzle mulai membaik. Guru menggunakan langkah-langkah penerapan terapi permainan puzzle yang sudah dijelaskan diatas. Ketiga anak yang mengalami hiperaktif ini mulai memperhatikan gurunya pada saat guru menjelaskan, sudah mulai tidak berterik-terik didalam kelas pada saat belajar, sudah bisa mengontrol kaki dan tangannya agar tidak bergerak pada saat membaca buku, iqra' atau pada saat dikursi, mulai tidak mengganggu temannya pada saat di kelas dan diluar kelas, dan sudah paham dengan arahan guru.

Setelah dilakukan upaya yang maksimal dari kedua guru di kelas A dengan berdasarkan langkah-langkah serta indikator yang sesuai dengan anak yang hiperaktif dan penanganan guru terhadap anak yang hiperaktif dengan tepat maka proses yang dilakukan guru benjalan dnegan lancar dan sesuai dengan hasil yang diinginkan guru agar anak yang hiperaktif tersebut dapat berubah menjadi anak yang dapat mengontrol sosial emosional dengan dibantu guru dengan terapi permainan puzzle tersebut, penulis juga mendapati hasil data observasi akhir sebagai berikut:

\section{Tabel 2. Data Akhir Anak Hiperaktif Kelompok A di TK Swasta IT Jabal Noor Medan Krio}

\begin{tabular}{|c|c|c|}
\hline No & Nama & Perubahan Tingkah Laku Anak \\
\hline \multirow[t]{6}{*}{1.} & \multirow[t]{6}{*}{ Aisyah } & $\begin{array}{l}\text { Ketika aisyah sedang membaca buku dan iqra' sudah mulai } \\
\text { tenang karena pembiasaan terapi permainan puzzle tersebut. ia } \\
\text { dapat mengontrol dirinya agar tetap tenang pada saat membaca. }\end{array}$ \\
\hline & & $\begin{array}{l}\text { Aisyah sudah mampu mempertahankan perhatian saat } \\
\text { mengerjakan tugas karena jika aisyah tidak mempertahankan } \\
\text { perhatiannya saat mengerjakan tugas maka permainan puzzle } \\
\text { tidak akan diberikan oleh gurunya. }\end{array}$ \\
\hline & & $\begin{array}{l}\text { Setelah guru memberikan permainan puzzle kepada Aisyah ia } \\
\text { dapat duduk dengan tenang dan tidak bermain tangan dan } \\
\text { kakinya atau bergerak-gerak. }\end{array}$ \\
\hline & & $\begin{array}{l}\text { Aisyah dapat mempertahankan perhatian dan penjelasan dari } \\
\text { guru }\end{array}$ \\
\hline & & $\begin{array}{l}\text { Aisyah dapat mengontrol pembicaraan dengan temannya pada } \\
\text { saat mengerjakan tugas. }\end{array}$ \\
\hline & & $\begin{array}{l}\text { Setelah guru memberikan permainan puzzle kepada Aisyah. } \\
\text { Maka Aisyah dapat duduk dengan tenang dan tidak berpindah- } \\
\text { pindah tempat. }\end{array}$ \\
\hline \multirow[t]{2}{*}{2.} & \multirow[t]{2}{*}{ Daffa } & $\begin{array}{l}\text { Daffa mulai tenang ketika sedang membaca buku dan iqra'. } \\
\text { Karena setelah daffa membaca guru memberikan permainan } \\
\text { puzzle tersebut agar daffa semnagat untuk membaca. }\end{array}$ \\
\hline & & $\begin{array}{l}\text { Daffa sudah mampu mempertahankan perhatian saat } \\
\text { mengerjakan tugas. Karena pada saat bermain puzzle anak harus }\end{array}$ \\
\hline
\end{tabular}

Strategi Guru Dalam Menangani Anak Yang Hiperaktif Melalui Terapi Permainan Puzzle Pada Kelompok A di Tk Swasta It Jabal Noor Medan Krio 
http://jurnaltarbiyah.uinsu.ac.id/index.php/raudhah

e-mail: jurnalraudhah@uinsu.ac.id

p-ISSN: 2338-2163

e-ISSN: $2716-2435$

\begin{tabular}{|c|c|c|}
\hline & & $\begin{array}{l}\text { menggunakan konsentrasi yang tinggi, maka dari itu daffa sudah } \\
\text { mulai teliti dan fokus dalam mengerjakan tugas. }\end{array}$ \\
\hline & & $\begin{array}{l}\text { Daffa sudah mulai mengontrol tangan dan kaki atau bergerak } \\
\text { dikursi karena guru sudah memberikan terapi atau pembiasaan } \\
\text { permainan puzzle. }\end{array}$ \\
\hline & & $\begin{array}{l}\text { Daffa sudah dapat mempertahankan perhatian dan penjelasan } \\
\text { dari guru karena pada saat bermain puzzle membutuhkan } \\
\text { konsentrasi yang tinggi dan perhatian yang tinggi untuk } \\
\text { menyelasaikan permainan tersebut }\end{array}$ \\
\hline & & $\begin{array}{l}\text { Anak dapat mengontrol pembicaraan dengan temannya pada } \\
\text { saat mengerjakan tugas. }\end{array}$ \\
\hline & & $\begin{array}{l}\text { Daffa sudah dapat duduk dengan tenang dan tidak berpindah- } \\
\text { pindah tempat ketika guru meemberikan permainan puzzle } \\
\text { untuk diselesaikan oleh daffa. }\end{array}$ \\
\hline & & $\begin{array}{l}\text { Daffa dapat tenang dan tidak berlari- lari pada saat proses } \\
\text { pembelajaran karena guru sudah melakukan terapi permainan } \\
\text { puzzle terhadap daffa, ketika daffa harus menyelesaikan } \\
\text { tugasnya untuk menyusun kepingan puzzle daffa harus tenang } \\
\text { dan tidak berlarian untuk menyelesaikan permainan tersebut, } \\
\text { maka dari itu setelah terapi permainan puzzle daffa dengan } \\
\text { tenang menyelesaikan tugasnya dan tidak berlarian lagi. }\end{array}$ \\
\hline & & $\begin{array}{l}\text { Setelah guru memberikan permainan puzzle dan Daffa } \\
\text { diperintahkan untuk menyelesaikan permainan tersebut. maka } \\
\text { daffa sudah dapat tenang dan tidak berteriak-teriak saat bermain. }\end{array}$ \\
\hline & & Anak sudah dapat mengikuti arahan dari guru. \\
\hline 3. & Naufal & $\begin{array}{l}\text { Naufal mulai tenang ketika sedang membaca buku dan iqra'. } \\
\text { Karena setelah naufal membaca guru memberikan permainan } \\
\text { puzzle tersebut agar daffa semnagat untuk membaca. }\end{array}$ \\
\hline & & $\begin{array}{l}\text { Daffa sudah mampu mempertahankan perhatian saat } \\
\text { mengerjakan tugas. Karena pada saat bermain puzzle anak harus } \\
\text { menggunakan konsentrasi yang tinggi, maka dari itu daffa sudah } \\
\text { mulai teliti dan fokus dalam mengerjakan tugas. }\end{array}$ \\
\hline & & $\begin{array}{l}\text { Setelah guru memberikan permainan puzzle kepada } \\
\text { naufal. Maka naufal sudah mulai mengontrol tangan dan kaki } \\
\text { atau bergerak dikursi ketika mengerjakan tugas dari guru. } \\
\text { Contohnya menyelesaikan kepingan puzzle tersebut hingga } \\
\text { selesai, dimulai dari pembiasaan naufal menyelesaikan } \\
\text { permainan puzzle tersebut. maka ketika ia menyelesaikan tugas } \\
\text { yang lain dari guru naufal dapat tenang dan tidak } \\
\text { menggoyangkan kaki nya dikursi. }\end{array}$ \\
\hline & & $\begin{array}{l}\text { Setelah guru melakukan terapi permaiann puzzle naufal dapat } \\
\text { memperhatikan guru saat menjelaskan didepan, karena pada saat } \\
\text { naufal melakukan terap permainan puzzle sampai dengan } \\
\text { selesai, naufal membutuhkan perhatian yang sangat besar, maka } \\
\text { dari itu ketika guru menjelaskan didepan kelas naufal dapat } \\
\text { memperhatikan dengan baik karena sudah terbiasa fokus dan } \\
\text { teliti saat menyelesaikan permain puzzle. }\end{array}$ \\
\hline
\end{tabular}

Strategi Guru Dalam Menangani Anak Yang Hiperaktif Melalui Terapi Permainan Puzzle Pada Kelompok A di Tk Swasta It Jabal Noor Medan Krio 
http://jurnaltarbiyah.uinsu.ac.id/index.php/raudhah

e-mail: jurnalraudhah@uinsu.ac.id

p-ISSN: 2338-2163

e-ISSN: 2716-2435

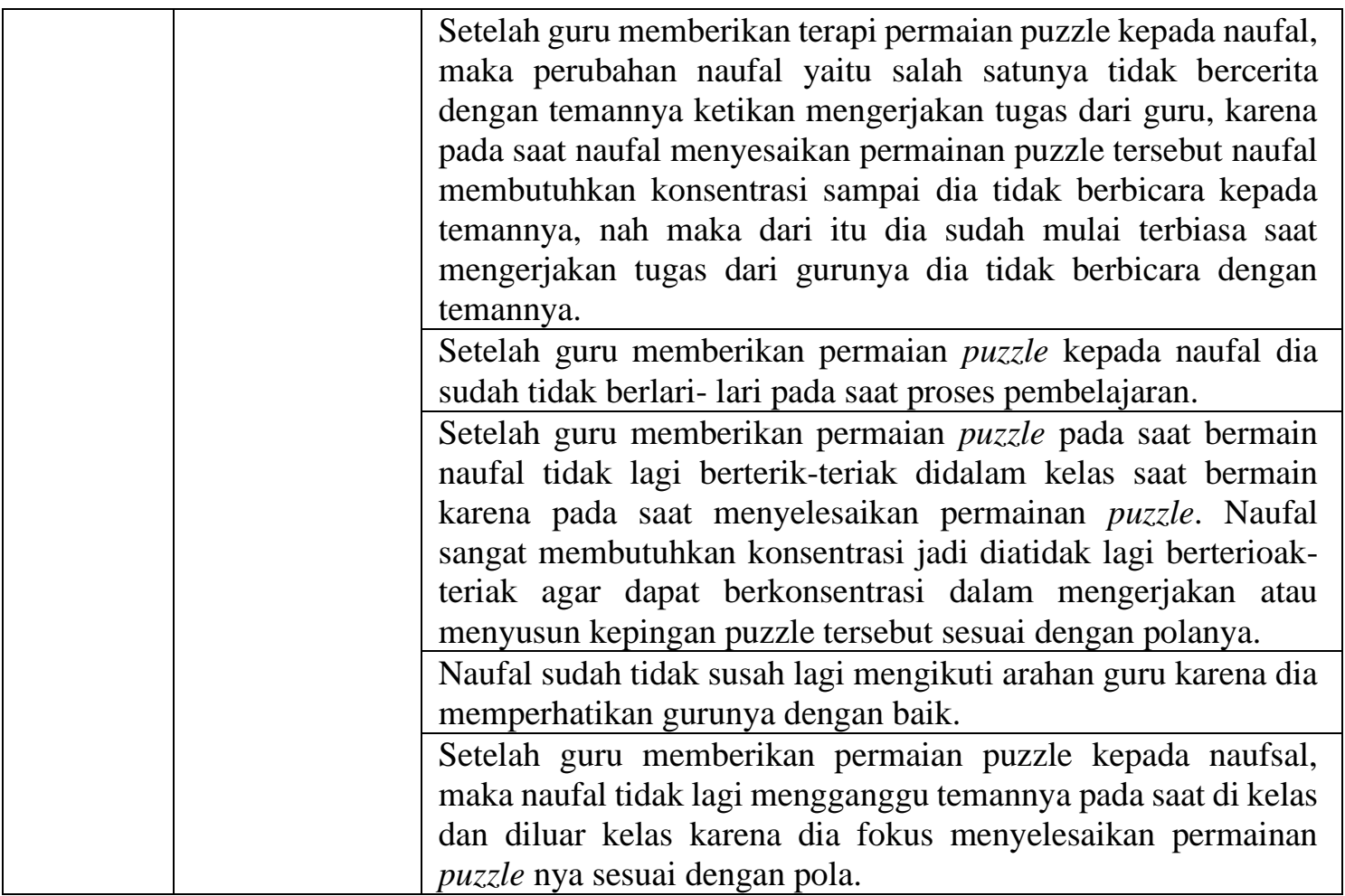

(Sumber : Hasil observasi pada saat survey di TK Swasta IT Jabal Noor Medan Krio)

Berdasarkan observasi penulis terhadap langkah-langkah guru dalam menangani anak yang hiperaktif melalui terapi permainan puzzle maka dapat disimpulkan penulis bahwasannya guru sudah berusaha semaksimal mungkin terhadap anak yang hiperaktif melalui penanganannya yaitu terapi permainan puzzle atau pembiasaan permainan puzzle denga diterapkan sesuai langkahlangkah penerapan terapi permainan puzzle dalam menangani anak yang hiperaktif di kelas A TK Swasta IT Jabal Noor.

Menangani anak yang hiperaktif itu sangat penting, karena jika anak yang hiperaktif tersebut hanya dibiarkan oleh guru maka dia anak mempengaruhi teman-temannya atau membuat dampak negative kepada murid lainnya, maka dari itu guru TK A melakukan perhatian khusus terhadap anak yang hiperaktif agar tidak memberikan dampak yang buruk baik anak hiperaktif tersebut dan siswa lainnya dengan melalukan terapi permainan puzzle terhadap anak hiperaktif.Cara saya mengetahui anak hiperaktif yaitu yang pertama saya membaca beberapa jurnal atau referensi lainnya untuk mencari ciri-ciri anak hiperaktif, lalu memperhatikan perilakunya secara terus menerus terhadap anak yang hiperaktif tersebut sesuai dengan ciri-ciri anak hiperaktif, mendekati serta memahami anak tersebut sehingga saya mengetahui bahwa anak itu mengalami perilaku hiperaktif dengan menunjukan sikap anak yang tidak bisa diam ketiga dikelas, sering mengganggu temannya di kelas,

Strategi Guru Dalam Menangani Anak Yang Hiperaktif Melalui Terapi Permainan Puzzle Pada Kelompok A di Tk Swasta It Jabal Noor Medan Krio 
http://jurnaltarbiyah.uinsu.ac.id/index.php/raudhah

e-mail: jurnalraudhah@uinsu.ac.id

p-ISSN: 2338-2163

e-ISSN: $2716-2435$

berteriak-teriak saat bermaian, berlari-lari ketika proses pembelajaran, tidak memperhatikan ketika guru menjelaskan didepan kelas, dan tidak dapat mengikuti perintah dari guru.

Sebelum guru melakukan penanganan terhadap anak yang hiperaktif maka saya menyediakan alat dan bahan untuk penanganan anak hiperaktif seperti menyiapkan puzzle dari bahan gabus dan bahan seperti kardus, puzzle berkarakter gambar atau foto mereka satu kelas sehingga bisa menarik perhatian anak untuk menyelesaikan permainan puzzle. Metode yang saya gunakan dalam menangani anak hiperaktif yaitu salah satunya dengan terapi permainan puzzle berkarakter foto mereka satu kelas karena dengan menggunakan puzzle bisa menarik perhatian anak dan membuat anak lebih fokus untuk menyelesaikan kepingan-kepingan puzzle tersebut apalagi bentuk puzzle nya merupakan wajah mereka sendiri, maka dari itu mereka makin bersemangat untuk belajar dan mulai fokus dalam pembelajaran karena pengaruh terapi permainan puzzle karena ketika mereka menyelesaikan permainan puzzle tersebut harus menggunakan konsentrasi dan fokus yang baik, nah dari pembiasaan terapi permainan puzzle anak mulai fokus dan memperhatikan guru ketika menjelaskan di depan kelas.

Menggunakan metode bermain juga akan membuat anak lebih fokus dalam mengerjakan atau menyelesaikan pekerjaannya, anak dapat duduk tenang dikurs, tidak berlari-lari, karena bermain adalah dunia anak, maka dari itu guru harus kreatif membuat pemainan yang mendidik dan mempunyai manfaat untuk anak, agar ketika anak bermain tidak hanya bermain saja, ketika anak bermaian maka didalam permainan itu mempunyai makna dan kesan yang baik untuk anak. Seperti permainan puzzle yang dibuat sendiri oleh guru kelas A TK Swasta IT Jabal Noor, dari permainan puzzle membuat anak yang hiperaktif dapat mengontrol emosinal anak. Setelah sata melakukan semua langkah-langkah dalan menangani anak yang hiperaktif melalui terapi permainan puzzle saya melakukan evaluasi terhadap keberhasilan dalam menangani anak hiperaktif yang dilihat dari perubahan tingkah laku anak setelah melakukan terapi permainan puzzle.

Berdasarkan hasil wawancara kepada guru kelas A dapat disimpulkan bahwasannya guru telah berusaha semaksimal mungkin dengan mengidentifikasi dan menangani serta mengevaluasi perkemabngan perilaku anak hiperaktif setelah anak di berikan permainan puzzle. Untuk lebih jelas dan memperkuat bahwasannya terapi permainan puzzle dapat mempengaruhi tingkah langku dan membuat perubahan pada anak maka penulis melakukan wawancara terhadap orang tua anak yang mengalami hiperaktivitas. Yang pertama saya mewawancarai orang tua Aisyah yang menyatakan perubahan aisyah ketiak melakukan terapi permainan puzzle perubahan yang dikatakan oleh orang tua Aisyah yaitu ketika mengerjakan tugas dirumah aisyah sudah mulai tenang dan langsung mengerjakan tugasnya dengan baik, ketika duduk di kursi saat mengerjakan tugas dirumah kedua 
http://jurnaltarbiyah.uinsu.ac.id/index.php/raudhah

e-mail: jurnalraudhah@uinsu.ac.id

p-ISSN: 2338-2163

e-ISSN: 2716-2435

kaki aisyah tidak lagi bergerak-gerak. Lalu saya mewawancarai orang tua daffa yang menyatakan perubahan daffa yaitu daffa tidak lagi berbicara berlebihan pada saat bercerita, daffa dapat menyelesaikan tugas rumahnya dengan tenang, daffa juga mulai tidak berlarian ketika dirumah, dan daffa juga mulai tidak berteriak-teriak dirumah ketika bermain dengan teman rumahnya. Dan wawancara ketiga yaitu dnegan orang tua naufal yang menyatakan perubahan naufal yaitu naufal tidak lagi membantah perkataan orang tuanya dan dapat mengikuti arahan orang tuanya, naufal dapat membaca buku dan iqra' dirumah dengan tenang, dan dapat menyelesaikan tugasnya denga tenang tanpa di awasin orang tua.

\section{SIMPULAN DAN SARAN}

Berdasarkan hasil penelitian yang dilakukan tenang "Strategi Guru dalam Menangani Anak yang Hiperaktif Melalui Terapi Permainan Puzzle Pada Kelompok A di TK Swasta IT Jabal Noor Medan Krio Tahun Ajaran 2020/2021" dapat disimpulkan sebagai berikut:

1. Langkah-langkah yang dilakukan guru dalam menangani anak yang hiperaktif melalui terapi permainan puzzle pada kelompok A di TK Swasta IT Jabal Noor Medan Krio yaitu mulai dari guru memahami sepenuhnya tentang strategi guru untuk menangani anak yang hiperaktif. Pertama guru menyiapkan media yang hendak digunakan oleh guru untuk penanganan terhadap anak yang hiperaktif melalui terapi permainan puzzle, guru membuat kelompok kecil untuk anak yang ingin mengalami terapi permainan puzzle, membagikan kerangka puzzle, memandu anak untuk bermain puzzle, guru mempersilahkan siswa untuk melakukan permainan puzzle, melaksanakan evakuasi atas permainan yang telah dilakukan oleh anak.

2. Sarana dan Prasarana yang digunakan untuk strategi guru dalam menangani anak yang hiperaktif melalui terapi permainan puzzle pada kelompok A di TK Swasta IT Jabal Noor Medan Krio diantaranya ruang kelas, halaman, taman bermain, alat dan bahan atau media yang digunakan untuk penerapan terapi permainan puzzle yaitu papan puzzle.

3. Kendala guru dalam penerapan terapi permainan puzzle pada kelompok A di TK Swasta IT Jabal Noor Medan Krio yaitu kurangnya waktu untuk melakukan terapi permainan puzzle dan ada beberapa media puzzle yang tidak sesuai dengan usia anak karena permainan puzzle nya tidak menggunakan pola. Ada dua faktor pendukung strategi guru dalam menangani anak yang hiperaktif melalui terapi permainan puzzle pada kelompok A di TK Swasta IT Jabal Noor Medan Krio, yaitu : kemampuan guru dalam mengajar meggunakan sarana dan prasarana yang didukung pihak sekolah. Adapun saran dalam penelitian ini ditujukan kepada guru diharapkan untuk meningkatkan kualitas pembuatan media pembelajaran sesuai dengan usia anak, agar hasil

Strategi Guru Dalam Menangani Anak Yang Hiperaktif Melalui Terapi Permainan Puzzle Pada Kelompok A di Tk Swasta It Jabal Noor Medan Krio 
http://jurnaltarbiyah.uinsu.ac.id/index.php/raudhah

e-mail: jurnalraudhah@uinsu.ac.id

p-ISSN: 2338-2163

e-ISSN: 2716-2435

pembelajaran sesuai dengan yang diinginkan oleh guru dan orang tua dan Kepada orang tua diharapkan untuk lebih memberikan perhatian terhadap anak dan ikut serta membantu anak unuk mengatasi anak yang memiliki gangguan hiperaktivitas.

\section{DAFTAR PUSTAKA}

Alam, Abdi Fiptar. 2014. Pengaruh Layanan Bimbingan Dan Konseling Terhadap Siswa.

Arsyad, Junaidi. 2013. Metode Pendidikan Rasulullah SAW Inspirasi Bagi Guru Sejati.Medan: Perdana Publishing.

Baihaqi dan Sugiarmin. 2006. Memahami dan Menyikapi Anak ADHD. Bandung:Refika Aditama. Elan., dkk. 2014. Penggunaan Media Puzzle Untuk Meningkatkan Kemampuan Mengenal Bentuk Geometri. Vol. 2.

Fadillah, M. 2017. Bermain \& Permaianan Anak Usia Dini. Jakarta: Kencana. Hadist Shahih AlBukhari No.4402

Haidir dan Salim. 2012. Strategi Pembelajaran (Suatu Pendekatan Bagaimana Meningkatkan Kegiatan Belajar Siswa Secara Transformatif).Medan: Perdana Publishing.

Hidayati, Richma. 2018. Peran Konselor Sekolah Dalam Meningkatkan Konsentrasi Pada Siswa Hiperaktif (AHD).

Indriana, Dina. 2011. Ragam Alat Bantu Media Pengajaran. Yogyakarta: Diva PressAnggota IKAPI. Khadijah dan Armanila.2017. Bermain dan Permainan Anak Usia Dini.Medan:Perdana Publishing. Khadijah dan Lasmana Roha Sitompul.2020. Permainan Anak Usia Dini Dalam Perspektif Islam, Jurnal Pendidikan, Sejarah, dan Ilmu-ilmu Sosial, Vol. 4.

Kusumaningtyas,Ersta Lydia. 2010. Mengenal Sekilas Tentang Anak Hiperaktif. Vol. 6.

Kusumawati, Eny. Studi Kasus Perilaku Hiperaktif dan Faktor Penyebabnya Pada Siswa Kelas III SD Negeri Mranggen 05 Kecamatan Polokarto Kabupaten Sukaharjo.

Lestari, Dwi. 2014. Penangangan Anak Hiperaktif Melalui Terapi Permainan Puzzle kelompok KB PAUD Saymara Kartasura Tahun Ajaran2014/2015

M.A, Situmorang.2012. Meningkatkan Kemamampuan Memahami Wacana Melalui Media Pembelajaran Puzzle. Vol 1.

Maisarah. 2019. Matematika dan Sains Anak Usia Dini. Medan: Akasga Sakti.

Marlina. 2008. Gangguan Pemusatan Perhatian Dan Hiperaktif Pada Anak.Padang: UNP Press Padang

Mas, Kes. 2019. Peran Orang Tua Dan Guru Dalam Menangani Perilaku Hiperaktifitas

Strategi Guru Dalam Menangani Anak Yang Hiperaktif Melalui Terapi Permainan Puzzle Pada Kelompok A di Tk Swasta It Jabal Noor Medan Krio 
http://jurnaltarbiyah.uinsu.ac.id/index.php/raudhah

e-mail: jurnalraudhah@uinsu.ac.id

p-ISSN: 2338-2163

e-ISSN: $2716-2435$

Putri Pangesti Rahayu dan Suwarno. 2016. Efektivitas Penerapan Terapi Permainan Sosialisasi Untuk Menurunkan Perilaku Impulsif Pada Anak Dengan Attetion Deficit Hyperactive Disoeder (ADHD). Vol. 9.

Putri, Bawono Denada. 2019. Penanganan Anak Hiperaktif Melalui Permaina Puzzle Di TK Desa Sraten 01 Tahun Ajaran 2018/2019. Skripsi Pendidikan Anak Usia Dini.

Rasminim. 2018. Metodologi Penelitian:pendekatan Praktis Kualitatif. Yogyakarta:Mitra Cendikia. Rosma. 2019. Penangangan Anak Hiperaktif Melalui Terapi Permainan Puzzle (Studi Kasus) Di Tk Pratama Kids Sukabumi Bandar Lampung

Ulfa, Maria. 2015. Beragam Gangguan Paling Sering Menyerang Anak. Yogyakarta: FlasBooks.Pratiwi, Wiwik. 2017. Konsep Bermain Pada Anak Usia Dini. Vol. 5.

Strategi Guru Dalam Menangani Anak Yang Hiperaktif Melalui Terapi Permainan Puzzle Pada Kelompok A di Tk Swasta It Jabal Noor Medan Krio 